\title{
1032 SAFETY ON RURAL ROADS?
}

A D Aggarwal, ${ }^{*}$ M Garg, ${ }^{*}$ R K Gorea, ${ }^{*}$ A Singh ${ }^{*}$ Correspondence to Post Graduate Institute of Medical Sciences, 14 Desi Mehmandari Opposite to Bus Stand Patiala Punjab 147001, India

10.1136/ip.2010.029215.1032

Indian cities are definitely growing at a blinding pace. The population and traffic in cities are spiralling and the infrastructure is not able to cope up with the demand. All said and done, 'True India' still resides in the lap of Indian villages. The flavours, the colours, the vibrancy, the rich variety, the innocence that the Indian villages offer is truly breathtaking. This is true even for the issues in rural transport and road safety, where photos will depict the contraptions for transport that Villages in India have got to offer. The issue of rural transport safety has been simmering for quite some time. Until now safety issues in the transport sector have overwhelmingly concentrated on roads, highways and motorised traffic. We are advocating for more attention to rural transport safety issues, beyond roads; particularly in relation to public transport and gender. The geographical and economic isolation of rural communities is often exacerbated by a lack of political commitment to local mobility issues. As for many developing countries, rural road development has proven insufficient, often because little attention is paid to rural transport services. Enforcing the laws through stricter regulations, would mean that poor people would be marginalised and isolated even more as they would no longer be able to use the public transport or would have to pay fines, or even bribes. The photo study looks to highlight these issues to improve safety for poor people while still ensuring their access to critical lifelines and market opportunities. We will touch on issues of road safety, personal/commuter safety, pedestrian safety, road conditions, transport services, modes of transport, road rage, injuries in accidents, deaths, etc. We are interested to explore these themes and this opportunity will help to make these important issues more visible for policy and decision-makers. 